University of Nebraska - Lincoln

DigitalCommons@University of Nebraska - Lincoln

Faculty Publications: Department of Entomology

Entomology, Department of

June 1998

\title{
Adult Susceptibility of Nebraska Western Corn Rootworm (Coleoptera: Chrysomelidae) Populations to Selected Insecticides
}

\author{
Lance. J. Meinke \\ University of Nebraska-Lincoln, Imeinke1@unl.edu \\ Blair D. Siegfried \\ University of Nebraska-Lincoln, bsiegfried1@ufl.edu \\ Robert J. Wright \\ University of Nebraska-Lincoln, rwright2@unl.edu \\ Laurence D. Chandler \\ Northern Grain Insects Research Laboratory, Brookings, S.D.
}

Follow this and additional works at: https://digitalcommons.unl.edu/entomologyfacpub

Part of the Entomology Commons

Meinke, Lance . J.; Siegfried, Blair D.; Wright, Robert J.; and Chandler, Laurence D., "Adult Susceptibility of Nebraska Western Corn Rootworm (Coleoptera: Chrysomelidae) Populations to Selected Insecticides" (1998). Faculty Publications: Department of Entomology. 87.

https://digitalcommons.unl.edu/entomologyfacpub/87

This Article is brought to you for free and open access by the Entomology, Department of at DigitalCommons@University of Nebraska - Lincoln. It has been accepted for inclusion in Faculty Publications: Department of Entomology by an authorized administrator of DigitalCommons@University of Nebraska - Lincoln. 


\title{
Adult Susceptibility of Nebraska Western Corn Rootworm (Coleoptera: Chrysomelidae) Populations to Selected Insecticides
}

\author{
LANCE J. MEINKE, BLAIR D. SIEGFRIED, ROBERT J. WRIGHT, ${ }^{1}$ AND LAURENCE D. CHANDLER ${ }^{2}$
}

Department of Entomology, University of Nebraska, Lincoln, NE 68583-0816

\begin{abstract}
J. Econ. Entomol. $91(3)$ : 594-600 (1998)
ABSTRACT Topical bioassays were conducted in 1995 to estimate the susceptibility of adult western corn rootworm, Diabrotica virgifera virgifera LeConte, populations from Nebraska to technical grade methyl parathion, carbaryl, and bifenthrin. Significant differences in susceptibility occurred among populations for each insecticide. The largest relative differences in $L_{50}$ values between the most tolerant and susceptible field populations were 16.4- and 9.4-fold for methyl parathion and carbaryl, respectively. The $F_{1}$ colonies also exhibited significant differences in susceptibility to methyl parathion and carbaryl indicating that susceptibility traits are heritable. The response to bifenthrin (up to 4 -fold difference in $\mathrm{LD}_{50}$ values) was more homogeneous across populations than the response to the other 2 compounds. Populations with the largest $L_{50}$ values were located in 2 areas where adult management programs using carbamate and organophosphate insecticides have been extensively applied and control failures have been commonly reported. Results strongly suggest that corn rootworm management practices have selected for significant levels of resistance to methyl parathion, carbaryl, or both in certain areas of Nebraska.
\end{abstract}

KEY WORDS Diabrotica virgifera virgifera, resistance, methyl parathion, carbaryl, corn

Frewd CORN, Zea mays L., is the leading row crop in Nebraska and a major crop in the United States. In the western Corn Belt, growing corn in the same field for 2 or more successive years (continuous corn) is the best economic option for many producers. In continuous corn, root feeding by larvae of the western corn rootworm, Diabrotica virgifera virgifera LeConte, can cause substantial injury to corn plants (Sutter et al. 1990; Spike and Tollefson 1991a; Godfrey et al. 1993a, b) and reduce yields (Spike and Tollefson 1991b, Godfrey et al. 1993b). Crop losses and control expenses attributed to corn rootworms annually cost producers millions of dollars.

Insecticides are often applied to continuous corn to manage corn rootworms. One approach is to apply a soil insecticide at planting or 1st cultivation to control larvae in the root zone (Mayo and Peters 1978). An alternative strategy is to use a foliar insecticide to suppress adult corn rootworm populations and reduce egg laying so that larval populations will not cause economic loss the following season (Pruess et al. 1974).

In Nebraska, planting-time applications of soil insecticides were initially used during the late 1940s to

This article reports the results of research only. Mention of a proprietary product does not constitute an endorsement or a recommendation by USDA for its use.

${ }^{1}$ South Central Research and Extension Center, University of Nebraska-Lincoln, Box 66, Clay Center, NE 68933.

2 Northern Grain Insects Research Laboratory, USDA-ARS, 2923 Medary Avenue, Brookings, SD 57006. control corn rootworm larvae in continuous corn. Soil applications of organochlorine insecticides (e.g., BHC, aldrin, heptachlor) were commonly used by 1954 (Metcalf 1986). Ineffective control of western corn rootworm larvae was first detected in 1959 in south-central Nebraska. By 1963, high levels of resistance to aldrin had been documented (Ball and Weekman 1963), and a crisis developed because the insecticide products available to growers did not provide adequate corn rootworm control. The area infested with the resistant strain expanded rapidly, and by 1980 it covered most of the U.S. Corn Belt (Metcalf 1986). Western corn rootworm populations are still resistant to organochlorine insecticides, even though organochlorine insecticides have not been used for corn rootworm control for many years; this includes populations from geographic areas where the species has immigrated since organochlorine use ended (Siegfried and Mullin 1989).

When western corn rootworm resistance to organochlorine insecticides became apparent in the 1960s, producers in south-central Nebraska started to use aerial applications of insecticides to suppress beetle populations and subsequently manage larval damage the following season (Meinke 1995). Various studies demonstrated that adult corn rootworm populations could be greatly reduced by aerial applications of insecticides (Hill et al. 1948, Mayo 1976, Union Carbide 1977), and Pruess et al. (1974) documented that the adult corn rootworm management strategy could be used to prevent economic damage from larval feeding the following season. This practice, used in con- 


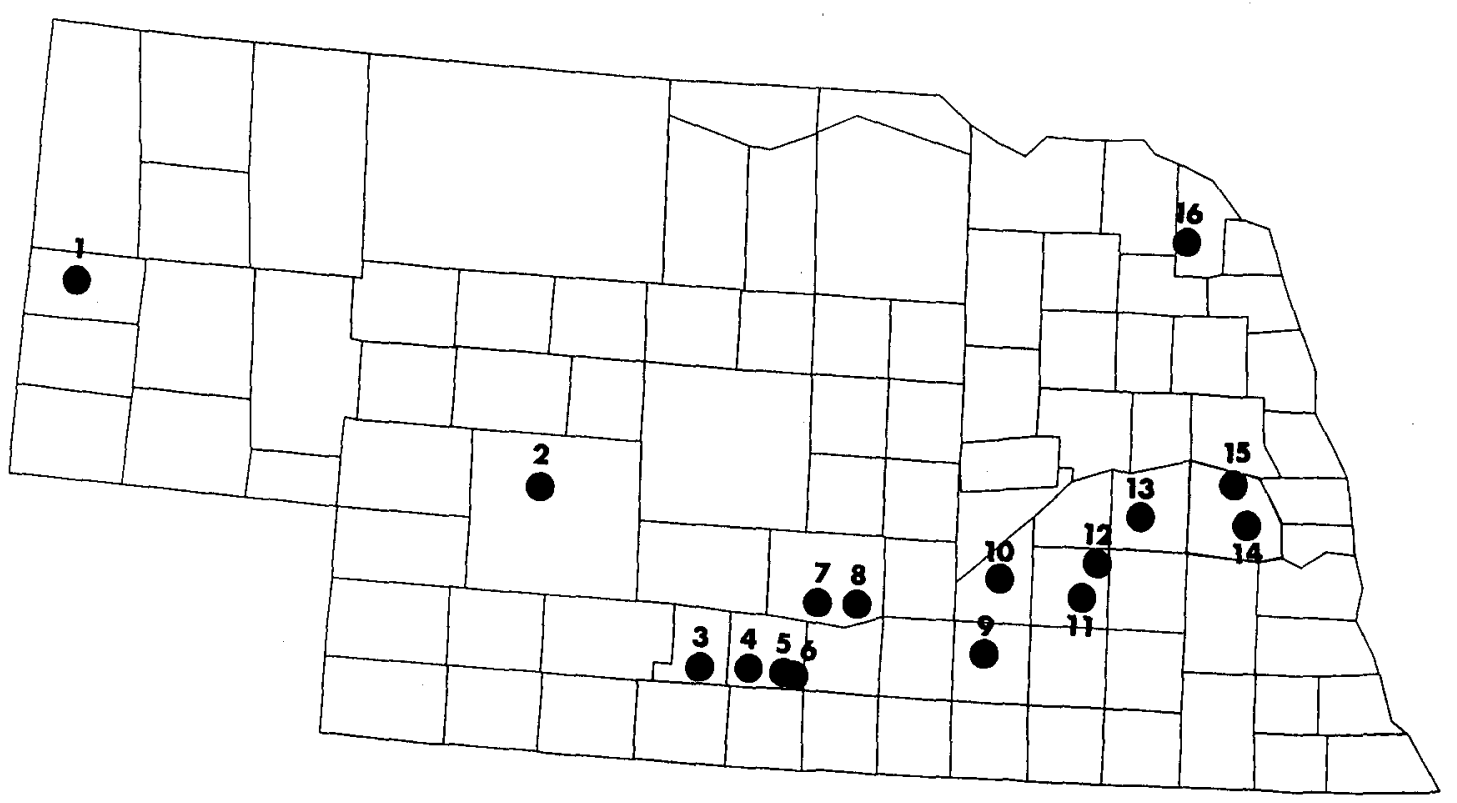

Fig. 1. Western corn rootworm collection sites in Nebraska.

junction with scouting of fields to determine beetle densities and to identify fields exceeding thresholds, is currently being used or recommended by a growing number of professional crop consultants in Nebraska and several other Corn Belt states (Meinke 1995).

Carbamate and organophosphate insecticides that eventually replaced the organochlorine insecticides were used extensively in Nebraska from the 1970s to early 1990s and generally provided good adult and larval corn rootworm control (no indication of resistance). Penncap M (encapsulated methyl parathion, Elf Atochem, Philadelphia, PA) is the most commonly used product for adult control in beetle spray programs because of its low price and relatively long residual activity in the field. Carbaryl (Sevin 4-Oil, Rhone-Poulenc, Research Triangle Park, NC) has historically been used for beetle control and now is the active ingredient in the recently introduced semiochemical-based bait SLAM (MicroFlo, Lakeland, FL) that also is registered for beetle control.

During the last $5 \mathrm{yr}$, reports of insecticide control failures have increased in parts of Nebraska where beetle spray programs have been used for many years (Wright et al. 1996). In some locations where Penncap $M$ is heavily used, both the rates of application and the number of applications per season have increased as a result of reduced product efficacy. In response to this situation, a project was initiated to determine if adult western corn rootworm populations had developed resistance to selected insecticides in Nebraska. This article reports the results of 1995 bioassays that were conducted to estimate the susceptibility of adult western corn rootworm populations from selected areas of Nebraska to 3 adult rootworm insecticides.

\section{Materials and Methods}

Insecticides. All insecticides used were technical grade and diluted with reagent grade acetone. Methyl parathion (99.0\% [AI]) was obtained from Chemical Services (West Chester, PA), carbaryl (99.8\% [AI]) was supplied by Rhone-Poulenc (Research Triangle Park, NC), and bifenthrin (91.3\% [AI]) was provided by FMC (Philadelphia, PA).

$F_{1}$ Colony Bioassays. Western corn rootworm beetles were collected in late August 1994 from a site in Phelps and Clay counties, NE (Fig. 1, numbers 6 and 9 , respectively). The Phelps County site was in an area where Penncap $M$ had been used extensively and poor beetle control had been reported. The Clay County population was collected from the University of $\mathrm{Ne}$ braska, South Central Research and Extension Center farm where, historically, only soil insecticides have been used for corn rootworm control. At least 500 beetles were collected per site and then shipped to the USDA-ARS Northern Grain Insects Research Laboratory in Brookings, $\mathrm{SD}$, where beetles were maintained for oviposition. Approximately 50,000 eggs were obtained from each population; standard procedures were used to collect and maintain eggs until termination of diapause and to rear $F_{1}$ individuals to adults (Jackson 1986).

The $F_{1}$ adults were shipped to the University of Nebraska and bioassayed with technical-grade methyl parathion and carbaryl. Each bioassay consisted of 5 insecticide doses plus an acetone control. All bioassays had at least 3 doses that caused a range of mortality $>0$ and $<100 \%$ for each colony. Each bioassay was replicated 3 times with 10 beetles per dose. This procedure was repeated twice for carbaryl and 3 times for methyl parathion on different days. Beetles were ran- 
Table 1. Susceptibility of laboratory-reared $F_{1}$ adult western corn rootworms to topically applied methyl parathion and carbaryl

\begin{tabular}{clcccc}
\hline \hline Population $^{a}$ & Nebraska county & $n$ & Slope $\pm \mathrm{SE}^{b, c}$ & $\mathrm{LD}_{50}(95 \% \mathrm{FL})^{b, d, e}$ & $\mathrm{LD}_{90}(95 \% \mathrm{FL})^{b, d, e}$ \\
\hline & & \multicolumn{5}{c}{ Methyl parathion } \\
6 & Phelps & 480 & $1.32 \pm 0.13 \mathrm{a}$ & $29.17(20.14-44.44) \mathrm{a}$ & $271(131.62-770.8) \mathrm{a}$ \\
9 & Clay & 509 & $1.94 \pm 0.21 \mathrm{~b}$ & $0.84(0.49-1.73) \mathrm{b}$ & $3.83(2.03-19.08) \mathrm{b}$ \\
& & & Carbaryl & \\
6 & Phelps & 300 & $1.54 \pm 0.20 \mathrm{a}$ & $123.62(54.70-237.6) \mathrm{a}$ & $842.3(338.2-6106) \mathrm{a}$ \\
9 & Clay & 300 & $1.44 \pm 0.14 \mathrm{a}$ & $18.89(14.35-24.81) \mathrm{b}$ & $146.0(97.06-256.0) \mathrm{b}$ \\
\hline
\end{tabular}

${ }^{a}$ Relative location of populations shown in Fig. 1.

${ }^{b}$ Values followed by the same letter within a column for each insecticide are not significantly different $(P>0.05)$.

c Significance of differences determined by likelihood ratio test for parallelism (Savin et al. 1977).

${ }^{d}$ Significance of differences determined by likelihood ratio test for equality followed by pairwise comparisons by using non-overlapping fiducial limits (Savin et al. 1977).

${ }^{e}$ Nanograms of toxicant per milligram insect.

domly selected from each colony and anesthesized by refrigeration. Male and female beetles were pooled because preliminary experiments indicated that there were no apparent differences in susceptibility among sexes (L.J.M. and B.D.S., unpublished data). Insecticide dilutions in acetone were applied to the ventral abdomen in a $0.5-\mu 1$ droplet, and control insects received $0.5 \mu \mathrm{l}$ of acetone. Beetles were provided with a moistened cotton dental wick and held at $22 \pm 0.5^{\circ} \mathrm{C}$ in constant darkness after treatment. Mortality was evaluated after $24 \mathrm{~h}$ and based on the inability of beetles to respond to probing. Thirty randomly selected beetles per colony were weighed during each bioassay to determine the mean insect weight that was used when calculating lethal dose values.

Field Survey. As a follow-up to the $F_{1}$ colony bioassays, field-collected beetles were bioassayed from populations obtained during the 26 July-24 August period from 16 sites across Nebraska (Fig. 1); 2,0003,000 beetles were collected at each site. Sites were selected to represent the major corn production areas of the state and to compare populations inside and outside of areas where beetle control problems had occurred. To obtain a representative sample of each population, collections were made before beetles were exposed to aerial insecticide applications and after a significant amount of adult emergence had occurred. Beetles were returned to the laboratory and maintained on a standard diet of lettuce, ground corn, and bee pollen to minimize potential differences in feeding history prior to collection. Initial bioassays were conducted within 2-5 d of field collection.

Western corn rootworm beetles were bioassayed with technical grade methyl parathion, carbaryl, and bifenthrin. These pesticides represent the 3 classes of insecticides currently used for beetle control. Bioassays were conducted as previously described for $F_{1}$ colonies except that each bioassay was replicated 4 times with 10 beetles per dose. The entire procedure was repeated twice on different days.

Statistical Analyses. Data were analyzed by probit analysis (Finney 1971) as adapted for PC use (POLOPC, LeOra Software 1987). The significance of differences among slopes for the populations bioassayed was determined by the likelihood ratio test for paral- lelism, and significance of differences among $\mathrm{LD}_{50}$ values was determined by the likelihood ratio test for equality with pairwise comparisons determined by nonoverlapping confidence intervals (Savin et al. 1977). For each insecticide in the field survey, correlation analysis (SAS 1985) was used to determine if there was a significant relationship between $L_{50}$ values and slopes of the dose mortality curves. A significance level of $P<0.05$ was used for all analyses.

\section{Results}

$F_{1}$ Colony Bioassays. The Phelps County population had significantly larger $L D_{50}$ and $L D_{90}$ values than the Clay County population for both methyl parathion and carbaryl (Table 1). The relative differences between population $L D_{50}$ and $L D_{90}$ values were much greater for methyl parathion (34.8- and 70.8-fold, respectively) than for carbaryl (6.5- and 5.8-fold, respectively). Slopes of the dose mortality curves were significantly different among populations in the methyl parathion bioassay but were parallel in the carbaryl bioassay (Table 1).

Field Survey. Bioassay data were obtained from 16 sites for methyl parathion (Fig. 1) , 15 sites for carbaryl (Fig. 1, number 6 not included), and 13 sites for bifenthrin (Fig. 1, numbers 3,6 , and 15 not included). Results indicate that susceptibility levels of western corn rootworm beetles to each insecticide were variable across collection sites (Tables 2-4). Methyl parathion, carbaryl, and bifenthrin $\mathrm{LD}_{50}$ values ranged from $0.49-8.08 \mathrm{ng} / \mathrm{mg}, 7.43-69.87 \mathrm{ng} / \mathrm{mg}$, and $0.24-$ $0.99 \mathrm{ng} / \mathrm{mg}$, respectively (Tables 2-4). Across populations, a significant correlation between $\mathrm{LD}_{50}$ values and slopes of the dose mortality curves occurred with methyl parathion $(r=-0.59, P=0.0165, n=16)$ but not with carbaryl $(r=-0.27, P=0.3246, n=$ $15)$ or bifenthrin $(r=0.38, P=0.1976, n=13)$. Five of the 7 populations with the largest methyl parathion $\mathrm{LD}_{50}$ values had slopes $<3.00$ (Table 2, numbers $4,6,10,12,13$ ) whereas the 9 populations with the smallest $\mathrm{LD}_{50}$ values had slopes between 3.00 and 5.10 (Table 2).

The largest relative differences in susceptibility among populations occurred with methyl parathion. 
Table 2. Susceptibility of field-collected adult western corn rootworms to topically applied methyl parathion

\begin{tabular}{clllc}
\hline \hline Population $^{a}$ & Nebraska county & Slope $\pm \mathrm{SE}^{b, c}$ & $\mathrm{LD}_{50}(95 \% \mathrm{FL})^{b, d, e}$ & $\mathrm{LD}_{90}(95 \% \mathrm{FL})^{b, d, e}$ \\
\hline 1 & Scottsbluff & $4.98 \pm 0.70 \mathrm{ab}$ & $0.57(0.51-0.70) \mathrm{d}$ & $1.08(0.89-1.39) \mathrm{d}$ \\
2 & Lincoln & $5.05 \pm 0.71 \mathrm{a}$ & $0.84(0.75-0.93) \mathrm{c}$ & $1.49(1.31-1.86) \mathrm{d}$ \\
3 & Gosper & $3.36 \pm 0.38 \mathrm{a}-\mathrm{f}$ & $0.72(0.43-1.22) \mathrm{cd}$ & $1.79(1.15-6.51) \mathrm{b}-\mathrm{d}$ \\
4 & Phelps & $2.64 \pm 0.30 \mathrm{e}-\mathrm{g}$ & $3.97(3.26-4.85) \mathrm{b}$ & $12.23(9.77-16.84) \mathrm{b}$ \\
5 & Phelps & $3.12 \pm 0.32 \mathrm{~b}-\mathrm{g}$ & $4.47(3.78-5.43) \mathrm{b}$ & $1.49(9.42-15.13) \mathrm{b}$ \\
6 & Phelps & $2.90 \pm 0.31 \mathrm{c}-\mathrm{g}$ & $8.08(6.68-9.55) \mathrm{a}$ & $22.32(17.99-29.96) \mathrm{a}$ \\
7 & Buffalo & $3.03 \pm 0.30 \mathrm{c}-\mathrm{g}$ & $0.86(0.78-1.02) \mathrm{c}$ & $2.34(1.88-3.13) \mathrm{c}$ \\
8 & Buffalo & $4.26 \pm 0.63 \mathrm{a}-\mathrm{c}$ & $0.82(0.74-0.99) \mathrm{c}$ & $1.64(1.40-2.22) \mathrm{cd}$ \\
9 & Clay & $3.56 \pm 0.34 \mathrm{a}-\mathrm{e}$ & $0.69(0.44-0.94) \mathrm{cd}$ & $1.57(1.07-3.21) \mathrm{cd}$ \\
10 & Hamilton & $2.63 \pm 0.33 \mathrm{~g}$ & $3.95(2.96-5.27) \mathrm{b}$ & $2.06(8.37-21.67) \mathrm{ab}$ \\
11 & York & $3.51 \pm 0.40 \mathrm{a}-\mathrm{e}$ & $6.11(5.20-7.11) \mathrm{a}$ & $14.21(11.69-18.49) \mathrm{ab}$ \\
12 & York & $2.67 \pm 0.23 \mathrm{~d}-\mathrm{g}$ & $6.15(3.68-10.18) \mathrm{ab}$ & $18.53(10.96-57.13) \mathrm{ab}$ \\
13 & Butler & $2.29 \pm 0.19 \mathrm{~g}$ & $2.78(1.89-4.03) \mathrm{b}$ & $10.12(6.51-21.66) \mathrm{ab}$ \\
14 & Saunders & $4.59 \pm 0.58 \mathrm{a}-\mathrm{c}$ & $0.75(0.68-0.90) \mathrm{cd}$ & $1.50(1.27-1.87) \mathrm{d}$ \\
15 & Saunders & $3.61 \pm 0.37 \mathrm{a}-\mathrm{e}$ & $0.49(0.25-0.80) \mathrm{cd}$ & $1.05(0.62-5.43) \mathrm{cd}$ \\
16 & Dixon & $4.19 \pm 0.56 \mathrm{a}-\mathrm{d}$ & $0.78(0.70-0.87) \mathrm{cd}$ & $1.56(1.30-2.00) \mathrm{cd}$ \\
\hline
\end{tabular}

${ }^{a}$ For each population, $n=400$; relative location of populations shown in Fig. 1.

${ }^{b}$ Values followed by the same letter within a column are not significantly different $(P>0.05)$.

${ }^{c}$ Significance of differences determined by likelihood ratio test for parallelism (Savin et al. 1977).

${ }^{d}$ Significance of differences determined by likelihood ratio test for equality followed by pairwise comparisons by using non-overlapping fiducial limits (Savin et al. 1977)

${ }^{e}$ Nanograms of methyl parathion per milligram insect.

The largest $\mathrm{LD}_{50}$ values for methyl parathion were recorded from populations in York (11 and 12) and Phelps (5 and 6) counties (Table 2). These populations were 9.1- to 16.4-fold more tolerant than the most susceptible population located in Saunders County (15). The $\mathrm{LD}_{50}$ values of populations 4-6 and $10-13$ were all significantly greater than the $\mathrm{LD}_{50}$ values of the remaining populations (Table 2). Populations 1-3, $7-9$, and $14-16$ were relatively susceptible to methyl parathion ( $<2$-fold difference in susceptibility).

Populations collected from the geographical areas with the largest methyl parathion $\mathrm{LD}_{50}$ values also had the largest carbaryl $\mathrm{LD}_{50}$ values (Tables 2 and 3 ). Populations 4, 5, 11 , and 12 had $\mathrm{LD}_{50}$ values 7.4- to 9.4-fold greater than the most susceptible population
(16). The carbaryl $\mathrm{LD}_{50}$ values of populations 4,11 , and 12 were significantly greater than the most susceptible populations (Table 3 , numbers $1,3,7-9,14-16$ ).

The dose responses of beetles to bifenthrin were more homogeneous across populations than either methyl parathion or carbaryl. Populations were relatively susceptible to bifenthrin; however, the largest bifenthrin $L D_{50}$ values occurred in the same geographical areas where the largest methyl parathion and carbaryl $\mathrm{LD}_{50}$ values were recorded (populations 4,5 , and $11-13$ were 2.8 - to 4.2 -fold more tolerant than the most susceptible population [8]). The $\mathrm{LD}_{50}$ values of populations 11-13 were significantly greater than the most susceptible populations (Table 4 , numbers 1 , $2,7-10,14$, and 16).

Table 3. Susceptibility of field-collected adult western corn rootworms to topically applied carbaryl

\begin{tabular}{cllcr}
\hline \hline Population $^{a}$ & Nebraska county & Slope $\pm \mathrm{SE}^{b, c}$ & $\mathrm{LD}_{50}(95 \% \mathrm{FL})^{b, d, e}$ & $\mathrm{LD}_{90}(95 \% \mathrm{FL})^{b, d, e}$ \\
\hline 1 & Scottsbluff & $3.76 \pm 0.51 \mathrm{a}$ & $10.86(9.16-12.67) \mathrm{c}$ & $23.83(19.65-31.96) \mathrm{d}$ \\
2 & Lincoln & $1.44 \pm 0.12 \mathrm{c}-\mathrm{f}$ & $23.40(8.76-55.56) \mathrm{a}-\mathrm{d}$ & $182.0(71.32-2451) \mathrm{a}-\mathrm{c}$ \\
3 & Gosper & $1.61 \pm 0.20 \mathrm{~b}-\mathrm{f}$ & $9.91(5.66-15.65) \mathrm{cd}$ & $61.85(35.71-157.3) \mathrm{c}$ \\
4 & Phelps & $1.19 \pm 0.12 \mathrm{ef}$ & $69.87(35.40-129.3) \mathrm{a}$ & $1422(556.5-9675) \mathrm{a}$ \\
5 & Phelps & $1.46 \pm 0.14 \mathrm{c}-\mathrm{f}$ & $54.95(11.15-165.5) \mathrm{a}-\mathrm{c}$ & $413.6(143.4-20599) \mathrm{a}-\mathrm{c}$ \\
7 & Buffalo & $1.77 \pm 0.15 \mathrm{~b}-\mathrm{d}$ & $12.16(6.36-21.18) \mathrm{cd}$ & $64.58(34.18-227.6) \mathrm{a}-\mathrm{c}$ \\
8 & Buffalo & $2.06 \pm 0.22 \mathrm{bc}$ & $9.04(2.61-18.72) \mathrm{cd}$ & $158.9(62.27-2140) \mathrm{c}$ \\
9 & Clay & $1.25 \pm 0.12 \mathrm{~d}-\mathrm{f}$ & $13.59(10.85-16.99) \mathrm{b}-\mathrm{d}$ & $68.02(49.92-102.5) \mathrm{c}$ \\
10 & Hamilton & $2.21 \pm 0.18 \mathrm{~b}$ & $22.38(16.28-30.86) \mathrm{b}$ & $85.26(56.84-159.8) \mathrm{c}$ \\
11 & York & $1.79 \pm 0.15 \mathrm{~b}-\mathrm{d}$ & $68.19(55.51-84.40) \mathrm{a}$ & $354.0(257.6-537.9) \mathrm{b}$ \\
12 & York & $1.70 \pm 0.14 \mathrm{~b}-\mathrm{e}$ & $61.70(41.33-94.33) \mathrm{a}$ & $351.3(201.1-904.1) \mathrm{ab}$ \\
13 & Butler & $1.82 \pm 0.16 \mathrm{bc}$ & $38.47(21.19-78.07) \mathrm{ab}$ & $194.9(93.76-1153) \mathrm{a}-\mathrm{c}$ \\
14 & Saunders & $1.41 \pm 0.13 \mathrm{c}-\mathrm{f}$ & $10.81(6.67-16.10) \mathrm{cd}$ & $86.23(50.77-203.0) \mathrm{c}$ \\
15 & Saunders & $1.13 \pm 0.11 \mathrm{f}$ & $12.72(8.81-17.75) \mathrm{b}-\mathrm{d}$ & $81.68(52.19-159.9) \mathrm{c}$ \\
16 & Dixon & $2.26 \pm 0.22 \mathrm{~b}$ & $7.43(6.04-8.98) \mathrm{d}$ & $192.5 \cdot(134.2-309.2) \mathrm{c}$ \\
\hline
\end{tabular}

${ }^{a}$ For each population, $n=400$ except population $\# 3$ where $n=200$; relative location of populations shown in Fig. 1.

${ }^{b}$ Values followed by the same letter within a column are not significantly different $(P>0.05)$.

${ }^{c}$ Significance of differences determined by likelihood ratio test for parallelism (Savin et al. 1977).

${ }^{d}$ Significance of differences determined by likelihood ratio test for equality followed by pairwise comparisons by using non-overlapping fiducial limits (Savin et al. 1977).

${ }^{e}$ Nanograms of carbaryl per milligram insect. 
Table 4. Susceptibility of field-collected adult western corn rootworms to topically applied bifenthrin

\begin{tabular}{cllc}
\hline Population $^{a}$ & Nebraska county & Slope $\pm \mathrm{SE}^{b, c}$ & $\mathrm{LD}_{50}(95 \% \mathrm{FL})^{b, d, e}$ \\
\hline 1 & Scottsbluff & $4.21 \pm 0.47 \mathrm{ab}$ & $0.42(0.37-0.49) \mathrm{ef}$ \\
2 & Lincoln & $3.34 \pm 0.31 \mathrm{a}-\mathrm{c}$ & $0.86(0.72-1.08) \mathrm{e}$ \\
4 & Phelps & $3.39 \pm 0.36 \mathrm{a}-\mathrm{c}$ & $\mathbf{1}(0.34-0.59) \mathrm{d}-\mathrm{g}$ \\
5 & Phelps & $3.17 \pm 0.32 \mathrm{a}-\mathrm{c}$ & $0.65(0.55-0.75) \mathrm{b}-\mathrm{d}$ \\
7 & Buffalo & $2.95 \pm 0.31 \mathrm{a}-\mathrm{c}$ & $0.71(0.61-0.83) \mathrm{bc}$ \\
8 & Buffalo & $2.51 \pm 0.31 \mathrm{c}$ & $0.37(0.31-0.44) \mathrm{fg}$ \\
9 & Clay & $3.51 \pm 0.33 \mathrm{a}-\mathrm{c}$ & $0.24(0.18-0.29) \mathrm{h}$ \\
10 & Hamilton & $4.02 \pm 0.61 \mathrm{a}-\mathrm{c}$ & $0.34(0.19-0.62) \mathrm{b}-\mathrm{h}$ \\
11 & York & $4.91 \pm 0.82 \mathrm{a}$ & $0.55(0.45-0.67) \mathrm{c}-\mathrm{e}$ \\
12 & York & $2.64 \pm 0.24 \mathrm{bc}$ & $0.81(0.71-0.92) \mathrm{ab}$ \\
13 & Butler & $3.99 \pm 0.49 \mathrm{a}-\mathrm{c}$ & $0.87(0.74-1.03) \mathrm{ab}$ \\
14 & Saunders & $3.02 \pm 0.37 \mathrm{a}-\mathrm{c}$ & $0.78(0.46-3.67) \mathrm{a}-\mathrm{e}$ \\
16 & Dixon & $3.15 \pm 0.49 \mathrm{a}-\mathrm{c}$ & $1.14(0.90-1.67) \mathrm{c}-\mathrm{e}$ \\
& & & $0.99(0.85-1.14) \mathrm{a}$ \\
& & & $0.39(0.32-0.46) \mathrm{e}-\mathrm{g}$
\end{tabular}

${ }^{a}$ For each population, $n=400$, except population $\# 10$ where $n=200$; relative location of populations shown in Fig. 1 .

${ }^{b}$ Values followed by the same letter within a column are not significantly different $(P>0.05)$.

${ }^{c}$ Significance of differences determined by likelihood ratio test for parallelism (Savin et al. 1977).

${ }^{d}$ Significance of differences determined by likelihood ratio test for equality followed by pairwise comparisons by using non-overlapping fiducial limits (Savin et al. 1977).

${ }^{e}$ Nanograms of bifenthrin per milligram insect.

\section{Discussion}

The results of this investigation strongly suggest that management practices used for control of western corn rootworm populations have selected for significant levels of resistance to methyl parathion, carbaryl, or both in certain areas of Nebraska. The significantly greater $L D_{50}$ values of populations from Phelps and York counties (see Fig. 1, numbers 4-6, 11, 12) are closely associated with the areas where control failures have been commonly reported. These counties, especially Phelps, include areas with a long history of continuous corn where the adult management strategy has been used for $>20 \mathrm{yr}$. Aerial applications of formulated carbaryl and more recently methyl parathion have placed annual selection pressure on beetle populations. In contrast, other areas of the state where the western corn rootworm remains susceptible to these compounds rely more extensively on soil insecticides or on crop rotation to manage rootworms. In areas where soil insecticides are commonly used, the selection pressures from this control strategy are probably less severe than adult management because the soil-applied insecticides protect only a portion of the roots (band or in-furrow application) allowing a significant proportion of the larval population to develop and emerge as adults (Sutter et al. 1991). The strong relationship between increased tolerance, areas of control failures, and long-term use of adult management programs provides convincing evidence that resistance has developed in rootworm populations in Nebraska.

The bioassays of $F_{1}$ progeny from the 1994 Phelps County collection exhibited higher levels of resistance to methyl parathion than seen in the 1995 bioassays of Phelps County field-collected beetles. The $\mathrm{F}_{1}$ colony results support our conclusion that resistance is present in certain areas of Nebraska especially because the trait is heritable. The $\mathrm{F}_{3}$ generation from the Phelps County population (Fig. 1, number 6) exhibits similar levels of resistance (L.J.M. and B.D.S., unpub- lished data). The higher levels of resistance detected in progeny of the 1994 Phelps County collection may be related to the timing of the initial field collection because beetles were collected in late August after the field had already received 2 applications of Penncap M. As a result, only the most resistant beetles were probably used to initiate the colony as opposed to the 1995 collections, which were obtained earlier in the season prior to insecticide applications. These results indicate that the level of resistance observed among 1995 field populations may not have reached a maximal level. This conclusion is supported by the significant correlation between susceptibility and slope of the $\log$ dose-mortality curves observed for methyl parathion. Significantly lower slopes observed for many resistant populations (Table 2) suggest that a higher degree of heterogeneity in toxicological response occurs in resistant than in susceptible populations. The relatively high proportion of susceptible genotypes still present in resistant populations also suggests that the resistance is still in the early stages of development.

It is difficult to draw any firm conclusions about the nature of the resistance at this time. Because the populations have been exposed to multiple active ingredients, it is not possible to distinguish between a single resistance mechanism that confers cross-resistance among different insecticide classes and multiple resistance mechanisms with broad effects. Significant levels of resistance to both carbaryl and methyl parathion suggest insensitivity of acetylcholinesterase, the target for both classes of insecticides (Matsumura 1985). However, populations exhibiting resistance to carbaryl and methyl parathion also exhibited elevated $\mathrm{LD}_{50}$ values for bifenthrin. Bifenthrin and other pyrethroids have not been used extensively in these areas, and it is unlikely that resistance has developed in response to these compounds. Therefore, the mechanism(s) that confer resistance to carbaryl and methyl parathion may be affecting bifenthrin susceptibility, 
which is more indicative of a nonspecific metabolic detoxification mechanism. Clearly, further investigation of resistance mechanisms in this species is essential to increase our understanding of the cross-resistance spectrum and to enable effective management decisions to be made.

Interestingly, sites identified with rootworm populations resistant to methyl parathion and carbaryl are in the same areas of Nebraska where cyclodiene resistance was first reported (Ball and Weekman 1963). At present, we believe that the resistant populations represent a very localized problem, as beetles collected from South Dakota, Iowa, and Kansas appear to be susceptible (unpublished data). However, given the historical spread of cyclodiene resistance in this species, management programs that minimize selection pressures and maintain the localized nature of the problem would seem to be warranted. Western corn rootworm resistance and subsequent control failures in Nebraska have had a significant impact on the affected areas. A number of aerial applicators are experimenting with new insecticide tank mixes, and there is a strong interest in finding economic alternatives to Penncap M. Many crop consultants in the affected areas are considering changes in rootworm management or have already recommended changes to clients. A number of growers have adopted soil insecticides as a management option, and some fields have been rotated out of corn for the first time in many years.

Rootworm resistance also has affected adult management programs that use behavioral baits that rely on cucurbitacins as feeding stimulants for delivery of the active ingredient carbaryl. For example, the bait formulation Slam was not marketed in Nebraska in 1996, and the utility of proposed areawide management programs relying on current behavior-based formulations has been viewed impractical for areas where resistance has been identified.

A better understanding of beetle movement, resistance inheritance patterns, and resistance mechanisms will improve our ability to make predictions about the potential spread of resistance. The relatively close proximity of susceptible and resistant populations (Fig. 1, numbers 3, 7, 8 versus 4, 5, 6, respectively) raises questions about the amount of population mixing that takes place in and around Phelps County. Beetle movement from population to population may be occurring at lower rates than might be expected based on the species known ability to migrate (Coats et al. 1986, Grant and Seevers 1989).

It is also important to understand the relationship between adult and larval corn rootworm susceptibility to insecticides within affected areas because most currently registered soil insecticides are in the same insecticide class (i.e., organophosphates) as methyl parathion. Preliminary laboratory bioassays indicate that larval progeny from methyl parathion-resistant adults are more tolerant than progeny from susceptible adults to the active ingredients in selected soil insecticides, but the intensity of this relationship varies across compounds within and among insecticide classes (L.J.M. and B.D.S., unpublished data). Growers in most of the Corn Belt rely on soil insecticides to manage corn rootworms in continuous corn; thus, the current resistance situation could have regional implications if resistant populations eventually move into other states.

Currently, resistance monitoring techniques are being developed to document more clearly the extent and distribution of the resistance problem in Nebraska. As the situation is more completely understood, we will be in a better position to identify appropriate strategies to follow to minimize the spread and negative impacts of the problem.

\section{Acknowledgments}

We acknowledge the contributions of G. R. Sutter that set the stage for this formal project. We thank J. Brown, T. DeVries, G. Hein, C. Darnell, T. Malousek, J. Christensen, D. Spray, J. Schwenk, and J. Almond for assistance when making beetle collections; Buffalo Air Service, A. Christiansen, J. Campbell, K. Clymer, J. Dey, B. Dunavan, G. Hall, G. Hein, D. Hendrickson, K. Jarvi, M. Kottmeyer, D. Oerter, Y. Reddy, E. Schwartz, R. Seymour, G. Vandell, and J. Witkowski for assistance in locating collecting sites; D. Hovland and D. Hartman for rearing $F_{1}$ colonies; and $K$. Lytle and $R$. Spawn for laboratory assistance when conducting bioassays. We thank S. T. Kamble and M. T. Scharf for their critical reviews of the manuscript. This research was supported in part by grants from BASF, Elf Atochem, FMC, Rhone-Poulenc, and ZENECA; the research also was supported by the USDAARS Northern Grain Insects Laboratory, and University of Nebraska Agricultural Experiment Station projects 17-058 and 48-022. This is paper No. 11981 of the Journal Series of the University of Nebraska Agricultural Research Division and contribution No. 959 of the Department of Entomology, University of Nebraska, Lincoln.

\section{References Cited}

Ball, H. J., and G. T. Weekman. 1963. Differential resistance of corn rootworms to insecticides in Nebraska and adjoining states. J. Econ. Entomol. 56: 553-555.

Coats, S. A., J. J. Tollefson, and J. R. Mutchmor. 1986. Study of migratory flight in the western corn rootworm (Coleoptera: Chrysomelidae). Environ. Entomol. 15: 620625.

Finney, D. J. 1971. Probit analysis. Cambridge University Press, Cambridge.

Godfrey, L. D., L. J. Meinke, and R. J. Wright. 1993a. Impact of western corn rootworm (Coleoptera: Chrysomelidae) larval injury on field corn gas exchange parameters. J. Econ. Entomol. 86: 1546-1556.

1993b. Field corn vegetative and reproductive biomass accumulation: response to western corn rootworm (Coleoptera: Chrysomelidae) root injury. J. Econ. Entomol. 86: $1557-1573$.

Grant, R. H., and K. P. Seevers. 1989. Local and long-range movement of adult western corn rootworm (Coleoptera: Chrysomelidae) as evidenced by washup along southern Lake Michigan shores. Environ. Entomol. 18; 266-272.

Hill, R. E., E. Hixson, and M. H. Muma. 1948. Corn rootworm control tests with benzene hexachloride, DDT, nitrogen fertilizers, and crop rotations. J. Econ. Entomol. 41: $392-401$. 
Jackson, J. J. 1986. Rearing and handling of Diabrotica virgifera and Diabrotica undecimpunctata howardi, pp. 2547. In J. L. Krysan and T. A. Miller [eds.], Methods for the study of pest Diabrotica. Springer, New York.

LeOra Software. 1987. POLO-PC. A user's guide to probit analysis or logit analysis. LeOra Software, Berkeley, CA.

Matsumura, F. 1985. Toxicology of insecticides, 2nd ed. Plenum, New York.

Mayo, Z B. 1976. Aerial suppression of rootworm adults for larval control. Department of Entomology Report 2. University of Nebraska, Lincoln.

Mayo, Z B, and L. L. Peters. 1978. Planting vs. cultivation time applications of granular soil insecticides to control larvae of corn rootworms in Nebraska. J. Econ. Entomol. 71: 801-803.

Meinke, L. J. 1995. Adult corn rootworm management. Univ, Neb. Agric. Res. Div. Misc. Publ. 63.

Metcalf, R. L. 1986. The ecology of insecticides and the chemical control of insects, pp. 251-297. In M. Kogan [ed.], Ecological theory and integrated pest management practice. Wiley, New York.

Pruess, K. P., J. F. Witkowski, and E. S. Raun. 1974. Population suppression of western corn rootworm by adult control with ULV malathion. J. Econ. Entomol. 67: 541545.

SAS Institute. 1985. SAS user's guide: statistics, 5th ed. SAS Institute, Cary, NC.

Savin, N. E., J. L. Robertson, and R. M. Russell. 1977. A critical evaluation of bioassay in insecticide research: likelihood ratio tests of dose-mortality regression. Bull. Entomol. Soc. Am. 23: 257-266.
Siegfried, B. D., and C. A. Mullin. 1989. Influence of alternative host plant feeding on aldrin susceptibility and detoxification in western and northern corn rootworms. Pestic. Biochem. Physiol. 35: 155-164.

Spike, B. P., and J. J. Tollefson. 1991a. Response of western corm rootworm-infested corn to nitrogen fertilization and plant density. Crop Sci. 31: 776-785.

1991b. Yield response of corn subjected to western corn rootworm (Coleoptera: Chrysomelidae) infestation and lodging. J. Econ. Entomol. 84: 1585-1590.

Sutter, G. R., J. R. Fischer, N. C. Elliott, and T. F. Branson. 1990. Effect of insecticide treatments on root lodging and yields of maize in controlled infestations of western corn rootworm (Coleoptera: Chrysomelidae). J. Econ. Entomol. 83: 2414-2420.

Sutter, G. R., T. F. Branson, J. R. Fisher, and N. C. Elliott. 1991. Effect of insecticides on survival, development, fecundity, and sex ratio in controlled infestations of western corn rootworm (Coleoptera: Chrysomelidae). J. Econ. Entomol. 84: 1905-1912.

Union Carbide. 1977. Proceedings 3rd adult corn rootworm management workshop, 1-2 February, Kansas City, MO. Union Carbide, Salinas, CA.

Wright, R. J., L. J. Meinke, and B. D. Siegfried. 1996. Corn rootworm management and insecticide resistance management, pp. 45-53. In Proceedings 1996 Crop Protection Clinic. Univ. Nebr. Coop. Ext.

Received for publication 28 July 1997; accepted 4 February 1998. 